\title{
An inside view: A Cuban trainee's journey
}

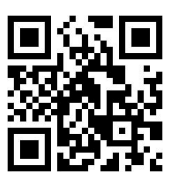

When Desmond Kegakilwe, of Tlhakgameng in the North West Province, was recruited in 1998, he had no idea what medical acrobatics he would have to perform to safely overcome the obstacles a poorly thought-out Cubantraining policy would place in his path.

One of the second-ever, 49-strong batch of Cuban-trained candidates, Kegakilwe is one of just 9 who have stuck it out in the public health sector. He had no idea when he boarded a 17-hour flight for Cuba that he would be studying in Spanish, no information on how his lack of South African-appropriate skills would be augmented when he returned, nor any idea whether his qualification would even be recognised. The culture of the Caribbean island where he spent 5 years was as foreign to him as the stigma he encountered upon returning home.

Today, 10 years after first entering the South African public healthcare system as an intern, Kegakilwe is working for the University of the Witwatersrand Reproductive Health Institute, (WRHI), training and mentoring Nurse-Initiated Management of Antiretroviral Therapy (NIMART). It's a tribute to his tenacity and adaptability, given that he received virtually no training in HIV or tuberculosis in Cuba. 'The fact that I'd never seen a full-blown TB $\mathrm{X}$-ray in Cuba doesn't mean I can't learn here, he pointed out.

Now the chairperson of the Rural Doctors Association of South Africa, (RUDASA), Kegakilwe was voted one of last year's Mail \& Guardian 200 Top Young South Africans. He mentors professional nurses at 29 clinics in the vast subdistrict of Ngaka Modiri Molema in Mafikeng, North West Province, covering up to 8 facilities a week and spending one day a week in the hospital to keep my clinical skills sharpened'. He refuses to give up the fight for good rural healthcare, 'because 
then I would have to leave medicine'. How else, he asks, would one be able to deliver wheelchairs or oxygen to remote villages, refer the abused and mentally unhealthy to appropriate institutions or help blind people get an education?

\section{From disaster to partially effective?}

Kegakilwe, now 33, describes the inception of South Africa's Cuban-trained doctor programme as 'a disaster'. Mpumalanga experimentally dispatched 10 rural students to Cuba, 9 of whom got through the first 5 years with one repeating a year. Emboldened, the national health department sent 49 cleareyed recruits, including Kegakilwe, to Centra provinces (Santo Spiritus, Santa Clara and Cienfuegos) in late February 1998. Ten of them returned home within 2 years. The remainder told the then national health minister, Nkosazana Zuma, that acquiring a proper working knowledge of Spanish within 6 months was impossible. She extended this to a year, promising to iron out the technicalities of how they would be registered as doctors with the Health Professions Council of South Africa (HPCSA) and to organise training augmentation upon their return.

'By the time I left Cuba in 2003, most of those problems had been ironed out,' says Kegakilwe. However, once back home, his rough ride continued. 'There was no clear policy to say you would stay in this (South African) university, for so long. The campuses differed in the length of time they were willing to take us on - there was lots of politics.' In contrast to the uniform Cuban medical curriculum, South African medical schools have different curricula, posing unique challenges for augmenting Cuban medical training. Without knowledge of the Cuban medical education system, it was also difficult for South African educators to identify gaps in the trainees' knowledge. If he had a magic wand, says Kegakilwe, he'd charm the local medical school deans into collectively identifying these gaps and sharing this across campuses, to create uniform integration. He took 15 months to secure his South African qualification, while many of his Cuban-trained compatriots needed the full 18 months available to them.

\section{Initial public sector retention: $62 \%$}

Of the 49 students in Kegakilwe's group, 7 quit within their first 3 months in Cuba; 3 failed first year twice and were thus excluded;

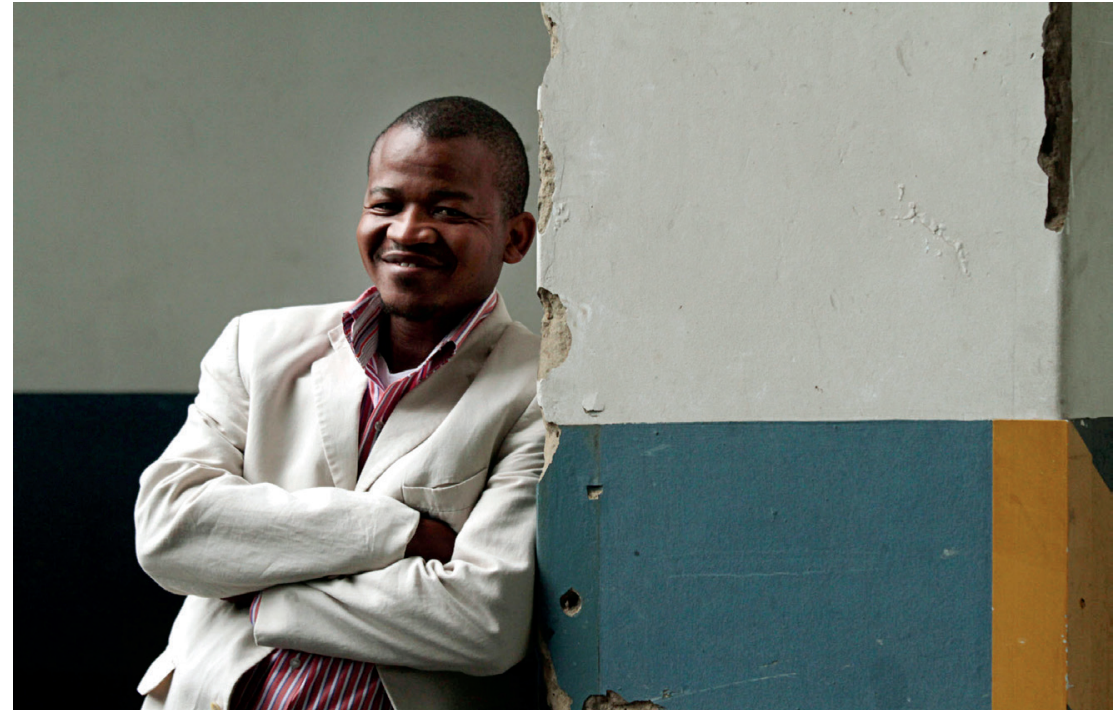

Cuban-trained Dr Desmond Kegakilwe, chairperson of the Rural Doctors Association of South Africa (RUDASA).

and 27 passed their fifth year to return to South Africa, (of whom 15 had repeated their first year), and went on to qualify both for Cuban and South African practice. Eight are now public sector registrars, and 2 are general practioners in private practice. Of the remaining 17 , all are working in their rural districts of origin, with 15 working as medical officers (MOs) in the public sector and 2 as MOs with NGOs.

Kegakilwe says that, from 2004, the number of Cuban-trained returnees failing the South African final exam has increased, in spite of incremental improvements in integration. 'Most fall [fail] at the South African exam. If they can get through that, they generally pass the Cuban finals that follow' he said. Like many of his South African-trained colleagues, he contends that a dire lack of accountability means that most provinces 'have no idea' how many Cubantrained doctors are on their 'books', or how many abscond before their commitment is over.

He believes the reason most qualified returnees he knows leave the public sector is because of inefficient and dysfunctional hospital and provincial management. While he managed to 'change a lot of things' at the public sector facilities where he worked (a route that brought him into activism and eventually to the RUDASA chair), others had not, and 'absconded out of sheer frustration'. Kegakilwe claimed that many Cuban trainees were refused the opportunity to specialise, unless they chose family medicine. 'It's the push factors once we're in the system that cause most to leave, he believes.
Kegakilwe also remembers the 'horrible stories' that abounded at the University of Pretoria, where he completed his training, and in the various departments of health regarding the stereotyping and stigmatisation of Cuban-trained doctors. 'Often this came out when lecturers got onto talking politics and were not aware that among their audience were the so-called "Cubans". They'd talk about "useless returnees". The other students would turn their heads in surprise because they knew we were on the programme. When the lecturer realised, they'd quickly tell us we were "different" from the rest [of the returnees]. You never knew whether they meant it or not.'

\section{Local colleagues miss 'social context'}

Asked what he saw as the major differences between a Cuban-trained South African doctor and their 'home-educated' counterpart, Kegakilwe said the latter had a 'more scientific approach'. 'When we sit with them, the social context of disease is not really important to them. If you focus just on the scientific aspect, you miss the patient's social and cultural background. In terms of social context, the locally-trained guys lack the basics, but they're superior when it comes to drugs and the spectrum of diseases.' He defined knowledge as 'individual - people develop themselves.'

\section{Chris Bateman}

chrisb@hmpg.co.za

S Afr Med J 2013;103(9):605-606. DOI:10.7196/SAMJ.7328 